\title{
A model confirmatory of adherence behavior with standard medication treatment among patients with asthma in Medan- Indonesia
}

\author{
Arlinda Sari Wahyuni ${ }^{1, *}$, Rozaimah Zain Hamid ${ }^{2}$, Tamsil Syafiuddin ${ }^{3}$, Adang Bachtiar ${ }^{4}$, Sake Juli Martina ${ }^{2}$, and Rina \\ Amelia $^{1}$ \\ ${ }^{1}$ Department of Community Medicine Faculty of Medicine Universitas Sumatera Utara, Indonesia \\ ${ }^{2}$ Department of Pharmacology and Therapeutic Faculty of Medicine Universitas Sumatera Utara, Indonesia \\ ${ }^{3}$ Department of Pulmonology and Respiratory Faculty of Medicine Universitas Islam Sumatera Utara, Indonesia \\ ${ }^{4}$ Department of Health Administration and Policy Public Health School of Universitas Indonesia, Indonesia
}

\begin{abstract}
Asthma problems are often linked to treatment management factors which include the nonmaximal behavior of the patients and doctors. The adherence concept emphasizes a strong commitment between physicians and patients to achieve maximum behavior towards the treatment. This study aimed to construct a model of adherence to treatment of patients with asthma and also aimed to set a valid and reliable adherence measurement tool that might be applied to patients with asthma, particularly those who live in Medan-Indonesia.The study was quantitative research employed a cross sectional approach. The samples were 200 adult patients with asthma who receive standard asthma medications, patients with the stable condition and do not suffer from severe asthma or other comorbidities. The study performed a consecutive sampling of the technique which was obtained from physician's data (general/lung specialist). Data were analyzed by performing confirmatory analysis through Structural Equation Modelling analysis. The study produced a measurement model of asthma patients' adherence to the treatment among those who live in Medan. The study found that the asthma patients who live in Medan have good psychometric value (valid, reliable and fit to model): adherence I (beliefs, knowledge, and attitudes), adherence II (doctorpatient communication, actions, family support).
\end{abstract}

\section{Introduction}

The prevalence of asthma disease is increasing in developed countries and also in developing countries [1]. Studies in Indonesia is showing the various prevalence of asthma in Indonesia. Yunus [2] did a research about the prevalence of asthma in Jakarta using International Study of Asthma and Allergies in childhood (ISAAC) questionnaire in 2001 and 2008 with a cumulative prevalence of $11.5 \%$ in 2001 and $12.2 \%$ in 2008 . Other than that, the result of Riskesdas in 2007 stated that the prevalence of asthma in North Sumatera ranged from 3\% to $6.4 \%$ [3].

The principle of asthma management according to GINA 2011 is the treatment of the basic pathogenesis of asthma which is an inflammatory process in the respiratory tract. This management was done by giving an inhaled combination of the anti inflammatory agents (controller) such as corticosteroid and long acting bronchodilator (reliever) such as Long Acting B2 Agonis (LABA) which should be used even in stable asthma (not having exacerbations). In fact, there is still a lot of asthma patients with poor adherence to treatment [1]

Appropriate and adequate treatment of asthma depends on the treatment behavior of asthma patients and the doctors who treated them. Patient's treatment behavior is simply called compliance. Compliance is patient's obedience in following doctor's advice [4], but patient's obedience in compliance does not include the understanding of various aspects related to the treatment or management of the disease. If the treatment fails, then the patient is to blame. On the other hand, Bauman [5] put forward the concept of adherence, which can be used as an appropriate breakthrough in the management of asthma. Adherence is in principle different from compliance, although both express patient's obedience in following doctor's advice. Adherence is the behavior of patient's obedience with his doctor's advice, which includes understanding about his illness that is related to the management of it, therefore he will follow his doctor's advice consistently [5]. The application of adherence can be through good and effective

\footnotetext{
* Corresponding author: arlinda@usu.ac.id
} 
communication between patient and family with the doctors who treated them $[5,6]$. Therefore, doctors need to develop effective health communication techniques between doctors and patients [7].

Based on previously stated theories, the appropriate and adequate management of asthma requires the involvement of various factors present in patient's life and environment, and the achievement of controlled asthma is not solely dependent on the available drugs. Adverse effects of asthma disease that are very disadvantageous can occur due to neglecting involvement of adherence forming factors, so that its management becomes inappropriate. The results of a survey conducted by Asthma Insight and Reality in the Asia Pacific (AIRAPI) in various Asia's big cities in 2003 showed that asthma management was not maximal and had not reached the desired target. This fact also occurs among asthma patients in Indonesia, asthma management is generally inappropriate and inadequate. The results of Tamsil's [8] study in the allergy and immunology polyclinic of Muhammad Husni Hospital in Palembang, found that asthma patients using controller medications are only $51.9 \%$. The results of Marliza's [9] study from inhaled medication users showed that only $40 \%$ of the patients were adherent, $65 \%$ had the correct technique of inhalation therapy, $42.5 \%$ with appropriate doses of inhaled drugs, and $67.5 \%$ discontinued treatment immediately after subjective complaints disappeared.

Application of adherence concepts in the management or treatment of asthma patients is paramount to develop in order to overcome the problem of behavioral treatment in asthma patients. The low adherence behavior to the treatment (adherence of asthma patients to the management of the disease) needs to be treated well, therefore it is necessary to review the various forming factors for the attainment of adherence in the application of effective communication among doctors, patients, and their families especially in Indonesia. This study aims to obtain an adherence measurement tool for asthma management that has never been done in Indonesia.

\section{Method}

This research was preceded by the development stage of the research instrument. This approach is based onvarious literature /reference studies and profound interviews. Profound interviews were conducted on several people from lung specialists. The number of all informants / respondents needed is 10 respondents. However this number is also set based on data saturation. The implications of qualitative research is explorative, flexible, reflective, open, and keep evolving in accordance with the progress that occurred throughout the research [10]. The second stage of this research is a quantitative approach to determining the validity and reliability of the measurement tool that has been set in the first stage.

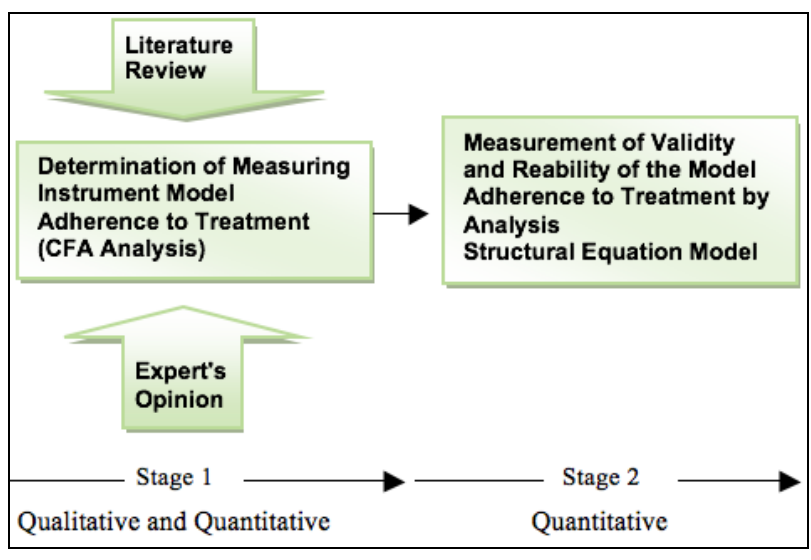

Fig. 1. Chart of reasearch's stages.

The population of this study is asthma patients who live in the city of Medan. Inclusion criteria is: adult asthma patients aged between 18-60 years, patients who visited general practitioner or lung specialist in Medan, patients who have been taking asthma treatment with standard medication (inhaled combination of corticosteroid with long acting $\beta_{2}$ agonists / LABA) for minimal 6 months, stable asthma patients (not having exacerbations), selected patients were patients with complete address data and willing to join this study (approved with informed consent). Exclusion criteria is: a history of coexisting diseases such as COPD (Chronic Obstructive Pulmonary Disease), heart diseases, diabetes mellitus, hypertension, kidney diseases, liver diseases, and history of allergy to medication used in this study, severe or moderate asthma patients or who is being hospitalized.

The samples of this study were some patients with asthma who were treated in the practice of general practitioners or lung disease specialists. Sampling technique in a research with quantitative approach is done by consecutive sampling, which is the process of sampling based on the criteria set by the researcher. Consecutive sampling is the best type of non probability sampling. Determination of the sample size is based on the hypothesis test for one proportion formula [11]. The number of samples in this study were 200 people.

The research were conducted by interviewing and completing questionnaire by respondents using a structured questionnaire. The basis of this technique is self-reporting the conditions experienced by asthma patients. Interviews and questionnaire were conducted after obtaining the patient's consent at the respondent's residence / home or at the place where the patient controls theirtreatment. The interviewer is the researcher in collaboration with students of the Faculty of Medicine in Universitas Sumatera Utara or nurses who have been trained by the researcher. Some interviewer officers demonstrated the technique of filling out the questionnaire in the presence of the researcher. This was done to obtain a valid data from asthma patients in this study. The time needed to collect the data was 14 months. Data analysis uses pearson correlation analysis to establish validity, and alpha cronbach value to establish data reliability. Apart from that, the researcher 
also uses confirmatory analysis to determine the validity and unidimensional of the measuring instrument that was analyzed. This analysis establishes the suitability of the model (goodness of fit) with some index such as chi square, cmindf, RMSEA, TLI, CFI, AGFI. The critical ratio value $p<0.05$ to determine the model's significance and loading factor to determine the unidimensional of each indicator [12-14].

Reliability indicates how much a measurement can yield relatively similar results when the repeated measurement was done on the same subject. Construct reliability is assessed by calculating the reliability index of the instrument used. The limit value used to assess a construct reliability is $>0.7$. Variance extracted limit value is $>0.5$ [12].

Ethical Clearance was obtained from Medical Research Ethics Commission of Medical Faculty at the Universitas Sumatera Utara. The respondents' participation is voluntary and they are entitled to be unwilling or to resign during the process of data collection.

\section{Results}

A qualitative approach aims to develop research instruments and a quantitative approach aims for instrument analysis. At this stage the researcher conducted a research with a qualitative explorative approach. This stage was done for approximately 6 months. Researcher assigned 10 informants from the medical community.

The selected informants from the medical community must meet the following criteria:

1) General practitioners or lung specialists who have understood the problems and managements of asthma patients

2) Have at least 3 years of experience in running specialist practice at home or in a hospital

3) Volunteered to be an informant for this research

The informants were 7 specialists and 3 general practitioners. Informants who come from specialists are doctors who undergo dual function, which is being a professional as well as a teaching staff at the Faculty of Medicine. Informants who come from general practitioners are doctors who also served as a teaching staff at the Faculty of Medicine. Of these 3 general practitioners, one of them is a patient with asthma and using inhalation drugs. Another one is a general practitioner with expertise in public health and the other one is a general practitioner with expertise in pharmacology. A number of male and female informants are equal to 5 people with a proportion of people aged $41-50$ years is 7 people.

\subsection{Demographic characteristics of asthma patients in Medan}

The following are characteristics of asthma patients in this study:
Table 1. Demographic characteristics of asthma Patients in Medan.

\begin{tabular}{|c|c|c|}
\hline Variable & $\mathrm{n}$ & $\%$ \\
\hline Age & & \\
\hline 330 & 88 & 44 \\
\hline $31-40$ & 33 & 16.5 \\
\hline $51-50$ & 41 & 20.5 \\
\hline Gender & 38 & 19 \\
\hline Male & 74 & 37 \\
\hline Female & 126 & 63 \\
\hline Education & & \\
\hline Primary School & 9 & 4.5 \\
\hline Junior High School & 11 & 5.5 \\
\hline Senior High School & 84 & 42 \\
\hline University & 96 & 48 \\
\hline Occupation & & \\
\hline Unemployed & 11 & 5.5 \\
\hline Housewife & 40 & 20 \\
\hline Student & 40 & 20 \\
\hline Civil Servant & 35 & 17.5 \\
\hline Private Employee & 28 & 14 \\
\hline Entrepreneur & 31 & 15.5 \\
\hline Etc & 15 & 7.5 \\
\hline
\end{tabular}

\subsection{Test result of validity and reliability of adherence in asthma patients}

Adherence to treatment of asthma patients consists of 2 latent variables which are Adherence I and Adherence II. Adherence I consists of 3 indicators that are knowledge, attitudes, belief in disease/treatment. Adherence II consists of 3 indicators that are actions, doctor-patient communication, and family support. Question items for knowledge consist of 9 questions. The question items for attitudes consist of 9 questions, for actions consist of 9 questions, and for doctor-patient communication consist of 20 questions. For beliefs and family support are 12 questions and 5 questions, respectively.

The following is the test resulf of validity and reliability from all indicators of quality of life in asthma patients. All indicators show the value of cronbach's alpha $>0.8$.

\subsection{Confirmatory factor analysis of exogenous construct (treatment adherence)}

For exogenous construct, confirmatory factor analysis is performed on two variables which is adherence variable I and adherence variable II. Adherence variable I consist of 3 indicators that are knowledge, attitudes, and beliefs disease / treatment and adherence II consists of actions, doctor-patient communication and family support. Results of data processing for confirmatory factor analysis of adherence construct are shown in the figure 2: 


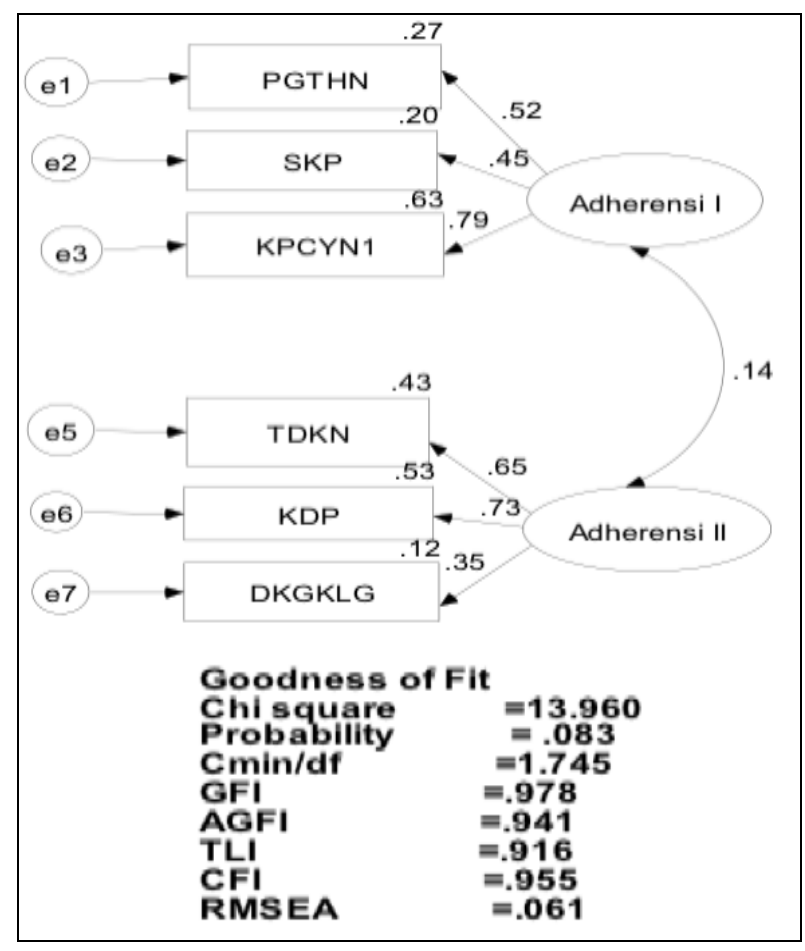

Fig. 2. Confirmatory factor analysis of adherence variable (exogenous)*.

* PGTHN: knowledge, SKP: attitudes, KPCYN1: beliefs, TDKN: actions, KDP: doctor-patient communication, DKGKLG: family support, Adherensi: Adherence

The table 2 describes the results of model's suitability test from exogenous variables and adherence to treatment based on model's conformity indices.

Table 2. Model's confomity test (goodness of fit) adherence variable.

\begin{tabular}{|c|c|c|c|}
\hline $\begin{array}{c}\text { Goodness of } \\
\text { fit index }\end{array}$ & Cut off value & $\begin{array}{c}\text { Analysis } \\
\text { result }\end{array}$ & $\begin{array}{c}\text { Model's } \\
\text { evaluation }\end{array}$ \\
\hline Chi Square & $\begin{array}{c}\text { Expected to } \\
\text { be small }\end{array}$ & 13.960 & Good \\
\hline Probability & $\geq 0.05$ & 0.083 & Good \\
\hline CMIN/DF & $\leq 1.96$ & 1.745 & Good \\
\hline GFI & $\geq 0.90$ & 0.978 & Good \\
\hline AGFI & $\geq 0.90$ & 0.941 & Good \\
\hline TLI & $\geq 0.95$ & 0.916 & Marginal \\
\hline CFI & $\geq 0.95$ & 0.955 & Good \\
\hline RMSEA & $\leq 0.08$ & 0.061 & Good \\
\hline
\end{tabular}

Model's evaluation results show a significance level of 0.083 . This shows that there is no difference between covariance matrix sample and the estimated population. This means the model is acceptable. Other conformity model indices such as CMIN/DF (1.745), GFI (0.98), AGFI (0.941), TLI (0.916), CFI (0.955), RMSEA $(0.061)$ provide sufficient confirmation that the above variables may reflect latent variables of adherence to treatment that were analyzed.

The result of a weighting factor significance test is shown in table 3 :
Table 3. Weighting factor significance test of adherence variable parameter.

\begin{tabular}{|c|c|c|c|c|c|}
\hline Relation & $\mathrm{E}^{*}$ & $S E$ & $C R$ & $p$ & Load \\
\hline $\begin{array}{l}\text { Knowledge } \\
\text { (adherence I) }\end{array}$ & 1.00 & & & & 0.52 \\
\hline Attitudes & & & & & 0.45 \\
\hline (adherence I) & 1.82 & 0.43 & 4.27 & 0.0001 & \\
\hline Beliefs & 203 & 056 & 361 & 00001 & 0.79 \\
\hline Actions & 100 & & & & 0.65 \\
\hline $\begin{array}{l}\text { Doctor-patient } \\
\text { communication }\end{array}$ & & & & & 0.73 \\
\hline (adherence II) & 1.65 & 0.52 & 3.17 & 0.0001 & \\
\hline $\begin{array}{l}\text { Family support } \\
\text { (adherence II) }\end{array}$ & 0.27 & 0.08 & 3.52 & 0.0001 & 0.35 \\
\hline
\end{tabular}

* E: Estimate

The significance test of weighting factor is by obtaining CR (Critical Ratio) and exogenous regression weight constructs from confirmatory factor analysis. The value of the regression coefficient for each indicator above is 1.96. Therefore a CR which is greater than 1.96 indicates that the variables are significant at $5 \%$ significance level and are the dimensions of the latent factor formed.

From table 3, lambda / loading factor value is seen from standardized estimates. Loading factor value for the six indicator variables describing adherence to treatment were $0.52,0.45,0.75,0.79,0.65,0.73,0.36$, respectively.

Exogenous regression weight constructs from confirmatory factor analysis can be indicated by loading factor of each indicator. The required lambda value is required to be $>40$ [14]. Furthermore, based on the confirmatory factor analysis of this treatment adherence construction, the model of this study could be used for further analysis without modification or adjustments.

\section{Discussion}

Psychometricians have established criteria for each measuring tools to be termed as a good measuring tool if the only itis able to provide reliable information. The criteria are reliable, valid, standard, economical, and practical. Validity means a level of accuracy from a measuring tool in performing the function of measuring [15].

Reliability test is intended to measure the level of consistency from the instrument used. Although reliability has various names such as trustworthiness, dependability, stability, and consistency, the central idea embedded in the concept of reliability is the extent to which a measurement can be trusted [15]. Sekaran in Azwar [15] said that the instrument is said to be reliable if the value of cronbach's alpha $\geq 0.6$. Instrument's reliability test result of treatment adherence I which is attitude and belief and treatment adherence II that is action, doctor-patient communication, and family support shows cronbach's alpha value $\geq 0.6$. However, knowledge only shows 0.585 of cronbach's alpha value. If the research is exploratory, then the value below 0.60 
is still acceptable along with the empirical reasons seen in the exploratory process [15]. This means that the questionnaires are sufficiently reliable to be used in assessing adherence to treatment, particularly in Medan with adult asthma patients using standard medications.

Adherence to treatment's questionnaires of asthma patients contains a comprehensive questionnaire to assess adherence to treatment with 6 dimensions of measurement that is knowledge, attitudes, beliefs, actions, doctor-patient communication, and family support with a total of 84 questions. Until now, to the best of the researcher's knowledge, there is no comprehensive questionnaires to assess adherence to treatment of asthma patients. The questionnaire was then shortened by the researcher to Adherence Asthmatic Patient Questionaire Medan (AAPQ-Medan). Cronbach's alpha test results in this questionnaire were 0.84 . Sekaran in [15] specify that this measuring tool is considered valid and reliable when the resulting cronbach's alpha value is $>0.6$. This means that the questionnaire is quite reliable to be used in particularly in Medan with adult asthma patients using standard medications. However, the weakness in this questionnaire is less practical because of too many question items ( 84 items). There should be further studies to examine and explore the question items in this study to produce a more simple measuring tool to explain the adherence to treatment in patients.

\subsection{Adherence to treatment variable's confirmatory analysis}

The confirmatory analysis is the latest method for testing validity and reliability of research's questionnaires. The way is calculating the loading factor which is a similar correlation between indicators with latent variables. When the loading factor obtained after the t-test is significant, it means the instrument is valid and reliable [16]. In this study, the researcher used this technique in testing the forming indicators of adherence totreatment in asthma patients. This is related to SEM analysis techniques that the researchers do. With SEM analysis techniques, the researcher can present a comprehensive model, that isthe ability of this technique toconfirm a concept or factor from dimensions as well as to measure the influence of theoretically existing relationship [17].

Evaluation results of adherence variable model indicate a significance level greater than 0.05 . This means there is no difference between covariance matrix sample and the estimated population so the model is acceptable / appropriate. In addition, conformity indexes such as Chi square, probability, CMIN/df, GFI, AGFI, CFI, RMSEA are in a good category. TLI value is still below the indicator that is below 0.95 . However, this criteria is still good because the TLI value for this model is in the marginal criteria. The above-mentioned index is an important index that can explain the measurement model that was being analyzed, especially the RMSEA which is an index that can be used on large samples with an assessment limit of $<0.08$. $[12,18,19]$.
In addition, the results of this study indicate the loading factor values for indicators that is knowledge, attitudes, beliefs (adherence to the treatment I) were $0.52,0.45,0.79$. While the loading factor values for indicators that are actions,, doctor-patient communication and family support (adherence to treatment II) were 0.68. 0.73, 0.35. From the results of this study it can be concluded that these six variables indicators together present unidimensional for latent variables of adherence to treatment (I and II). The results showed the loading value of adherence construct variables I and II $>0.4$, except the family support dimension with the loading factor value $<0.4$. Theoretically, the loading factor value between $\pm 0.30 \mathrm{~s} /$ d 0.40 is the minimum acceptable value [12], this means family support can be used as an indicator of adherence to treatment II. The highest loading factor value in adherence I and adherence II is beliefs and patient-doctor communication, respectively.

The strength of the dimensions causes the latent factor can be analyzed by using t-test against regression weight. Along with that,the results show a great value of $\mathrm{CR}$ (identical with $\mathrm{t}$ test) and the probability value is $<0.05$. The results of this test prove that the variables are significantly the dimension of the latent factor which is adherence to treatment that was formed.

Construct analysis in this research establishes two adherence constructs that were formed which is adherence I (knowledge, attitudes, and beliefs) and adherence II that is patient-doctor communication, actions, and family support. The construct that is formed is different from the planned concept. The concept of adherence is thought to be expressed from four indicators: knowledge, attitude, action, and doctorpatient communication. However, the results of the confirmatory factor analysis show that the forming dimension is not in the same dimension. The researchermade a model respecificationthat is to change the model with SEM model to be a good model. The analysis is developed by adding an adherence forming construct (which theoretically influences adherence to treatment) which isbeliefs and family support. Analytically, adherence I is formed from indicators of knowledge, attitudes and beliefs and adherence II is formed from actions, doctor-patient communication and family support. This finding means defining the best model in establishing adherence forming indicators. Therefore, it can be used as a reference for the best management of asthma by general practitioners or specialists.

Adherence to treatment variables forming indicators has shown unidimensionality. Furthermore, based on the confirmatory factor analysis of adherence to treatment variables, the model of this study can be used for further analysis which is full model analysis without modification or adjustments.

\section{References}

1. Global Initiative for Asthma, Global strategy for asthma management and prevention (2016) 
2. F. Yunus, M. Rasmin, D.K. Sutoyo, W.H. Wiyono, B. Antariksa, F. Fitriani, R. Sahril, J. Mustafa, T. Zulfikar, F. Alvian, J. Respir. Indo. 4, 176-180 (2011)

3. Health Office R.I., Basic Health Research Report of Province in North Sumatera (2007)

4. B. Smet, Health Psychology (Gramedia Widiasarana Indonesia, Jakarta, 1994)

5. A. Bauman, R. Borland, C. Brown, J. Cockburn, D. Hill, C. Rand, Asthma adherence, a guide for health professionals (National Asthma Council, Australia, 2005)

6. WHO, Adherence to Long Term Therapies: evidence for action (WHO Library Cataloguing-inPublication Data, Geneva, 2003)

7. S. Sarwono, Sociology of health. Some concepts and applications (Gadjah Mada University, Yogyakarta, 2004)

8. T.A. Tamsil, Adherence of asthma sufferers to the management of the disease in Polyclinic Allergy Immunology Internal Medicine RSMH Palembang Period December 2004 (Faculty of Medicine, Sriwijaya University, 2005)

9. Marliza, Asthma Treatment Profile at Puskesmas Kodya Medan (Specialist Doctor Education Program I Department of Lung Disease Science FK USU SMF Lung RSUP H Adam Malik Medan, 2005)

10. H. Patilima, Qualitative Research Method (CV Alfabeta, Bandung, 2005)

11. S. Lemeshow, D. Hosmer, J. Klar, S. Lwanga. Measure Sample in Medical Research (Gadjah Mada University Press, Jogyakarta, 1997)

12. J.F. Hair, R.E. Anderson, R.L. Tatham, W.C. Black, Multivariate data analysis (Pearson-Prentice Hall, USA, 2006)

13. Wibowo, Analysis Factor in Statistic Multivariate (2008)

14. A. Ferdinand, Structural Equation Modeling in management research (Diponegoro University Publishing Agency, Semarang, 2002)

15. S. Azwar, 2001. Reliability and validity (Pustaka Pelajar, Yogyakarta, 2001)

16. Sarmanu, Validity and Reliability of Research Instruments in Training Material of Structural Equation Modeling (Institute for Research and Community Service of Airlangga University, Surabaya, 2006)

17. Wibowo, Structural Equation Modeling (SEM) in Structuring Equation Modeling (Structural Equation Modeling) (Research Institute and Dedication of Masyaraat Universitas Airlangga, Surabaya, 2006)

18. S. Santoso, Structural Equation Modeling, Concepts and Applications with AMOS (PT Elex Media Komputindo Group Gramedia, Jakarta, 2007)
19. A. Widarjono, Applied multivariate statistical analysis (Publishing and Printing Unit, YKPN Management College, Yogyakarta, 2010) 